\title{
Cement-Based Mortar Panels Reinforced with Recycled Steel Fibers in Flexural Strengthening of Concrete Beams
}

\author{
Ziaaddin Zamanzadeh $^{1,2, *}$, Farzin Hosseinzadeh ${ }^{1}$, Mehdi Bashiri ${ }^{2}$ \\ ${ }^{1}$ Civil Engineering Department, Bostanabad Branch, Islamic Azad University, Bostanabad, Iran \\ ${ }^{2}$ Civil Engineering Department, Khazar University, Baku, Azerbaijan \\ Received 09 May 2021; received in revised form 25 June 2021; accepted 26 June 2021 \\ DOI: https://doi.org/10.46604/ijeti.2021.7623
}

\begin{abstract}
The effectiveness of a strengthening technique devised for the concrete beams subjected to bending is presented in this study, where recycled-steel fiber-reinforced mortar (RSFRM) panels are used as an eco-friendly replacement for ordinary steel fibers. Different mix designs for RSFRM are first investigated experimentally by testing $160 \times 400$ $\times 400 \mathrm{~mm}^{3}$ notched beam-like specimens in 3-point bending, while $100 \times 100 \times 100 \mathrm{~mm}^{3}$ cubes are tested in compression, to optimize the mix design. Finite element (FE) analyses are carried out on strengthened and non-strengthened beams to investigate the effectiveness of the proposed strengthening technique based on RSFRM panels. Starting from the tests on notched beams, an inverse FE analysis is used to optimize the RSFRM's parameters to be implemented into the numerical model. The results show that applying RSFRM panels not only markedly increases the load-bearing capacity of the beams (up to 3.19 times with $3 \%$ of fibers by volume), but also changes their fracture mechanism from brittle to ductile fracture.
\end{abstract}

Keywords: reinforced mortar, recycled steel fiber, finite-element analysis

\section{Introduction}

Reinforced concrete (RC) members may need strengthening for reasons such as change of usage, increase in service load, aging, and chemical aggressions [1]. On the other hand, much research has been carried out on the strengthening of concrete members due to their extensive use in structures, and various methods and materials have been proposed, such as externally attached steel plates, fiber reinforced polymers (FRP), etc. [2-3]. In addition to the increase in load bearing capacity, the strengthening techniques intend to improve the ductility of the concrete members [4].

Steel fibers are used extensively in mortar and concrete mixtures. Studies demonstrate that by properly utilizing the fibers, general behavior of the mortar and concrete members is improved, as crack propagation is arrested and energy absorption is increased [5]. The steel fiber type effect on the tensile behavior of fiber reinforced concrete (FRC) was studied using a new direct tensile test setup which reduces the stress concentration in specimens. The results demonstrated that the steel fibers improve the tensile capacity of FRC. However, the aspect ratio of fibers has a certain effect on the degree of tensile capacity improvement [6]. Adding steel fibers increases the compressive and flexural capacity of the concrete, however, it affects the bond between FRC and rebars. Therefore, a new bond model was developed using rebar pull out tests of concrete with different steel fiber volumes to predict the behavior of the reinforced FRC [7].

Steel fibers are one of the various types of fibers in concrete mixes used in construction. A remarkable portion of steel fibers is produced directly [8]. Besides consuming remarkable natural resources, the production of steel fibers has adverse environmental effects due to $\mathrm{CO}_{2}$ emission during the production [9-10]. In 2001, about 12M tones of reinforcement bars were

* Corresponding author. E-mail address: zzamanzadeh@khazar.org 
used per annum by the European concrete industry. Therefore, obtaining fibers from other indirect methods such as recycling end-of-life tires has attracted interests as a sustainable approach toward a green production. A significant number of studies have been dedicated to the evaluation of the effect of recycled steel fiber (RSF) in concrete behavior [11]. Despite some disadvantages such as low corrosion resistance, low workability, and difficulties in producing a uniform mixture of steel fiber, studies show that adding RSF improves the tensile, shear, and flexural behavior of the concrete, while the compressive strength hardly increases [12].

Using external concrete panels or mortar is one of the methods that has been proposed to repair the structural elements [1314]. Externally-added textile reinforced mortar (TRM), where mortar matrix is reinforced by textile fiber mesh, was used for shear and flexural strengthening of RC members. The results indicate that the ductility, shear, and flexural capacity of the strengthened members markedly increase. TRMs showed a high fire resistance, nevertheless, compared to the FRP laminates, this method was $7.2 \%$ and $8 \%$ less effective in shear and flexural strengthening, respectively [13-14]. TRMs were also extended to carbon TRMs (CTRMs) where carbon fibers are added to the mortar plates to strengthen the flexural capacity of concrete members [15]. The pre-stressed CTRMs were used to strengthen the pre-loaded RC beams subjected to flexure. Four-point bending tests were carried out on pre-loaded RC beams with and without CTRMS. The results demonstrated that the pre-stressed CTRMs increase the flexural load bearing capacity of the pre-loaded beams, and inhibit the crack propagation [16].

Steel fibers reinforced mortar was also used as an external strengthening method for structural member, such as beams and masonry walls [17-18]. The results prove the effectiveness of the steel fiber reinforced mortar in increasing strength and stiffness. Recycled steel fiber reinforced mortar (RSFRM) panels were used for shear strengthening of concrete beams. The proposed panels were connected to the concrete surface by means of epoxy adhesive and mechanical fasteners. Finally, the results illustrated the capability of the panels in increasing the load-carrying capacity of the beams [19].

Despite the remarkable potentials of the RSFs as a reliable alternative of steel fibers, there is a limited number of research on their application in structural strengthening. Mortar panels with RSF were used for shear strengthening, but there is no study in the literature dealing with the use of RSF as flexural strengthening of RC beams. This study represents a new application of panels produced by RSF for flexural strengthening. The proposed material is first investigated experimentally to obtain its properties, then numerical analyses are performed on strengthened concrete beams to examine their flexural load carrying capacity.

\section{Experimental Procedure}

\subsection{Materials}

The strengthening panels are produced by cement mortar and relatively high content of RSF. Specimens with five different mix designs are produced and tested to obtain the best fresh and hardened proportions of the mixing materials. Here, Portland cement type II, river fine aggregates (passing of sieve \#4), drinking water, RSF, and Mr. Fix SP $1000 \mathrm{~K}$ superplasticizer are used to produce the specimens. Moreover, limestone filler is used in some of the specimens to investigate its possible effects on the specimens. The RSFs extracted from waste tires by shredding process with an average diameter of $0.92 \mathrm{~mm}$ are used as the reinforcement (Fig. 1).

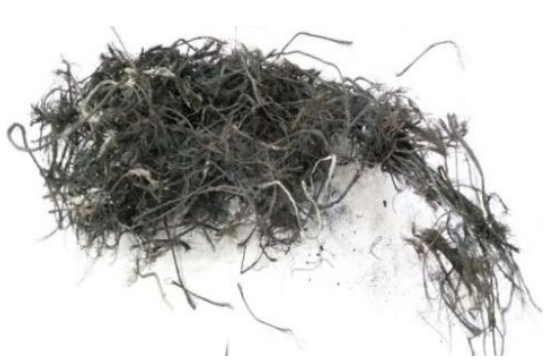

(a) Construction of one fiber

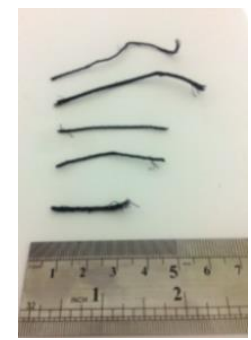

(b) RSF length

Fig. 1 The RSF extracted from waste tires 
Geometric properties of RSFs have been determined on a sample of 1000 fibers. The RSF length (the distance between the outer ends of the fibers) varies between $7.0 \mathrm{~mm}$ and $60 \mathrm{~mm}$, with an average value of $31.7 \mathrm{~mm}$. Fig. 2 indicates the graphical presentation of the ranges of RSF length. The largest number of length values is 31-45 mm (54.5\%) followed by the class $46-60$ $\mathrm{mm}(19.5 \%), 16-30 \mathrm{~mm}(16.5 \%)$, and 7-15 $\mathrm{mm}(9.5 \%)$.

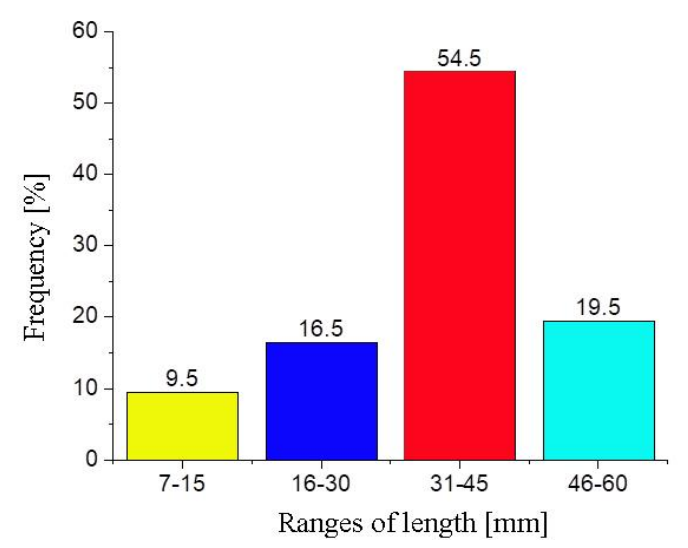

Fig. 2 Ranges of RSF length

\subsection{Mix designs}

Table 1 shows the details of the mix designs. The mix designs are named based on their constituents. The letter "L" denotes the specimen with the lime powder while "NL" indicates no limestone filler. The letter "F" represents that the mix design contains RFS. Also, the first number in each mix shows the volumetric percentage of the added fibers. To take care of the unavoidable dispersion of the results, three batches are produced for each mix design, and the average values of different properties are considered.

Table 1 Mix design details $\left(\mathrm{kg} / \mathrm{m}^{3}\right)$

\begin{tabular}{|c|c|c|c|c|c|c|}
\hline Mix design & Cement & Fine aggregate & Water (L) & Lime & RSF & Superplasticizer \\
\hline 1.5FL & 546.0 & 437.0 & 376.7 & 127.0 & 117.2 & 6.3 \\
\hline 1.5FNL & 655.0 & 445.0 & 376.7 & N/A & 117.2 & 6.3 \\
\hline 3FL & 528.0 & 454.0 & 376.7 & 120.0 & 263.7 & 8.0 \\
\hline 3FNL & 586.0 & 454.0 & 337.0 & N/A & 263.7 & 8.0 \\
\hline NFNL & 573.0 & 476.0 & 382.8 & N/A & N/A & N/A \\
\hline
\end{tabular}

\subsection{Casting of the specimens}

The specimens are produced based on the proposed mix designs. Dry materials are first put into a planetary mixer, and mixed during one minute properly. The water and superplasticizer are then mixed and added to the dried material, and mixed around two minutes until a uniform mixture is obtained. The technique for producing the specimens is based on the procedure proposed for producing slurry infiltrated fiber concrete (SIFCON) [20], in which the fibers are first placed into the mold, then the mortar is added. Finally, an external vibrator is used to achieve a uniform distribution of materials. The specimens are removed from the molds 48 hours after casting and are cured in the natural environmental conditions of the laboratory.

\subsection{Test setup}

Compressive and flexural tensile tests are conducted on each mix design to obtain an appropriate mix design to produce the strengthening panels. The peak load carrying capacities and flexural tensile load-displacement curves are obtained from the compressive and three-point bending tests, respectively. Compressive tests are performed on $100 \times 100 \times 100 \mathrm{~mm}^{3}$ according to BS 1881-116 (1983), and three-point bending tests are performed on the notched mortar $160 \mathrm{~mm} \times 40 \mathrm{~mm} \times 40 \mathrm{~mm}$ beams according to ASTM C348-20 standard. Also, each test is repeated five times to reduce the probable mistakes. The three-point 
bending test setup including the dimensions of the specimen and notch is shown in Fig. 3. The clear span of the tested beam is $100 \mathrm{~mm}$, and an external linear variable differential transformer (LVDT) is located in the middle of the beam to measure the deflection of the beam. Also, a notch is sawn into the bottom of the specimen to facilitate the crack formation and propagation.

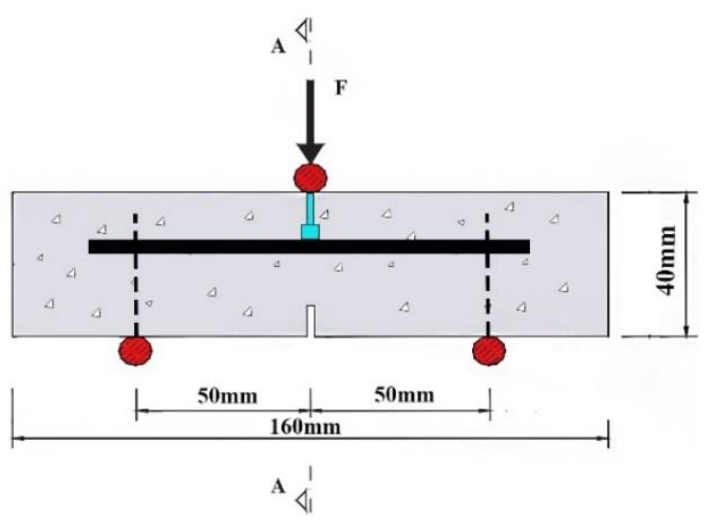

(a) Dimensions and loading condition

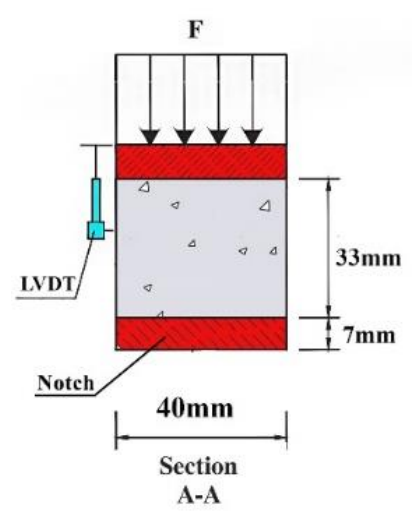

(b) Cross sectional view

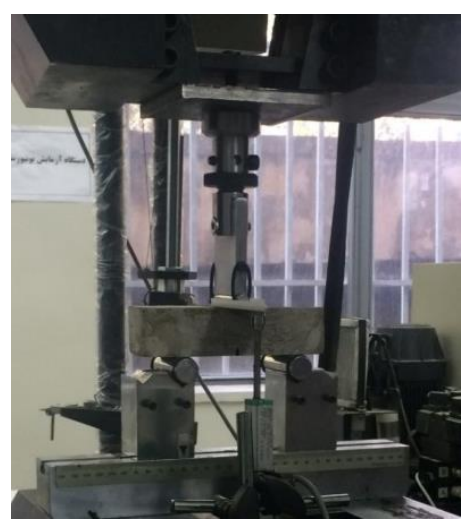

(c) Test setup

Fig. 3 Three-point bending test setup

\section{Finite Element (FE) Modeling}

Two-dimensional finite element (FE) analysis is carried out with FEMIX software [21] to investigate the behavior of the strengthened beams. An inverse analysis is first conducted on the experimental results to obtain the modeling parameters of the strengthening panel. The modeling parameters are then adopted in the FE model to simulate the behavior of the strengthened concrete beam by the panels under flexural test.

FE analysis is carried out based on the prediction of fracture mode1 propagation theory [22]. In this theory, the post-crack behavior is predicted by a trilinear softening diagram as represented in Fig. 4. The main parameters of the model are the fracture energy $G_{f}^{I}$, the ultimate fracture strain $\varepsilon_{n, i}^{c r}$, and $\sigma_{n, i}^{c r}$, which define the shape of the diagram determined by performing inverse analysis on experimental data.

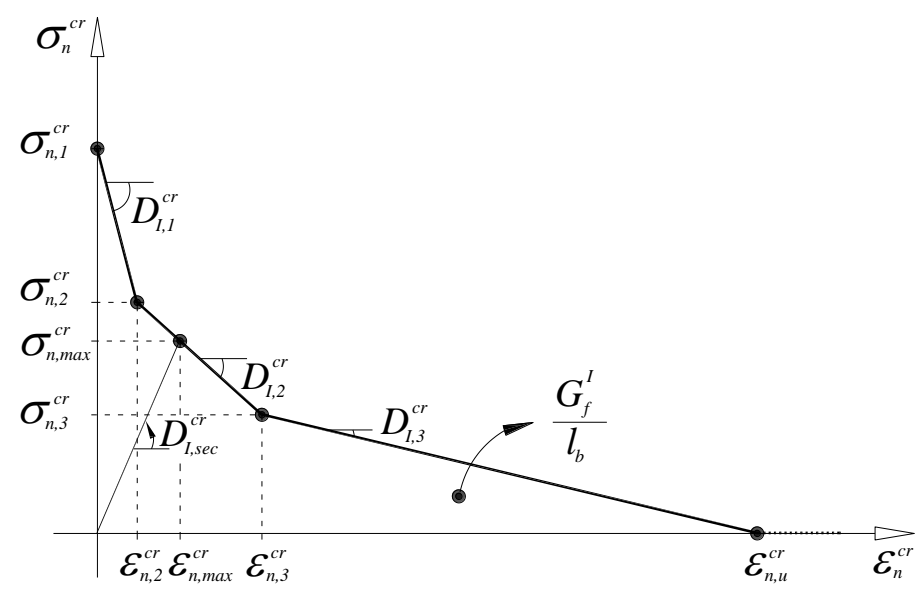

Fig. 4 Trilinear softening diagram [22]

Eq. (1) defines the ultimate fracture strain $\varepsilon_{n, u}^{c r}$ as a function of parameters including $\alpha_{i}, \xi_{i}$, the fracture energy $G_{f}^{I}$, the maximum tensile strength $f_{c t}$, and the crack bandwidth $l_{b}$ [23]. The crack bandwidth is used in a smeared crack method to make sure that the model is mesh-independence, and is assumed as a function of geometric characteristic of the used elements in $\mathrm{FE}$ analysis [22]. Here, $l_{b}$ is considered equal to the square root of the area of the integration point corresponding to the integration scheme adopted for the evaluation of the stiffness matrix and stress field. Furthermore, $\alpha_{i}$ and $\xi_{i}$ are indicated in Eqs. (2)-(5). 


$$
\begin{aligned}
& \varepsilon_{n, u}^{c r}=\frac{2}{\xi_{1}+\alpha_{1} \xi_{2}-\alpha_{2} \xi_{1}+\alpha_{2}} \frac{G_{f}^{I}}{f_{c t} l_{b}} \\
& \alpha_{1}=\sigma_{n, 2}^{c r} / \sigma_{n, 1}^{c r} \\
& \alpha_{2}=\sigma_{n, 3}^{c r} / \sigma_{n, 1}^{c r} \\
& \xi_{1}=\varepsilon_{n, 1}^{c r} / \varepsilon_{n, u}^{c r} \\
& \xi_{2}=\varepsilon_{n, 2}^{c r} / \varepsilon_{n, u}^{c r}
\end{aligned}
$$

In this context, 8-noded serendipity elements under a plane stress condition are selected to model the specimens. Gauss-Legendre approach with $2 \times 2$ integration points is applied for all elements except for the elements at the axis of symmetry of the specimens. For the elements which are at the symmetry axis, $1 \times 2$ integration point is considered to assure that crack propagates along the axis of symmetry [23].

Furthermore, the inverse analysis is performed to determine the required parameters of the trilinear diagram, i.e., $\alpha_{i}$, $\xi_{i}$, and $G_{f}^{I}$ by minimizing the differences between the numerical results and experimental data. Eq. (6) defines the error parameter where $A^{\text {exp }}$ and $A^{\text {num }}$ are the areas below the experimental and the numerical load-deflection curves, respectively [24].

\section{Results and Discussion}

\subsection{Experimental tests results}

The average load-deflection curves in 3-point bending of the control specimen and of the specimens with/without lime (FL and FNL, respectively) are shown in Fig. 5. The obtained values of the maximum flexural load capacity of the beams and cracking force are presented in Table 2. The cracking force is assumed as the load when a reduction of 10\% in initial secant stiffness occurred. The control beam shows a brittle failure with abrupt load decay after it reaches its maximum flexural capacity, while other specimens with fiber show a ductile behavior. The maximum tensile capacity of the specimens increases up to $72 \%$ by adding $3 \%$ of RSF. Though introducing lime powder into the fiber-reinforced specimens slightly increases the ductility of the specimen, it has a significant negative influence on the maximum flexural capacity of RSFRM. Table 2 also indicates the compressive test results of the RSFRM specimens. The results show that lime powder has an adverse effect on the compressive strength of RSFRM. Finally, among different mix designs, 3FNL is selected as the mix design of the strengthening panels due to its better flexural and compression behaviors.

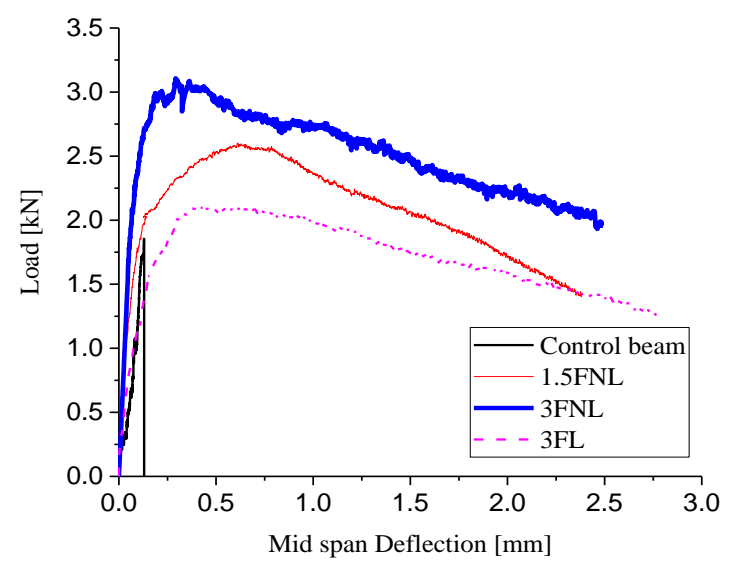

Fig. 5 Three-point bending test results of the specimens with different mix designs 
Table 2 Compressive and flexural test results of different mix designs

\begin{tabular}{|c|c|c|c|}
\hline $\begin{array}{c}\text { Specimen } \\
\text { type }\end{array}$ & $\begin{array}{c}\text { Average compressive } \\
\text { capacity (MPa) }\end{array}$ & $\begin{array}{c}\text { Cracking flexural } \\
\text { stress (MPa) }\end{array}$ & $\begin{array}{c}\text { Maximum flexural } \\
\text { stress (MPa) }\end{array}$ \\
\hline NFNL & 22.2 & 5.99 & 5.99 \\
\hline 1.5FL & 21.2 & N/A & N/A \\
\hline 1.5FNL & 22.5 & 6.94 & 8.43 \\
\hline 3FL & 20.7 & 5.44 & 6.81 \\
\hline 3FNL & 22.1 & 10.05 & 8.88 \\
\hline
\end{tabular}

\subsection{FE analysis}

Table 3 represents the parameters that minimized the error. The comparison between the FE analysis and the post tensile crack behavior of 3FNL is shown in Fig. 6. The result shows that the FE analysis effectively captures the test result.

$$
\text { error }=\frac{\left|A^{e x p}-A^{\text {num }}\right|}{A^{e x p}}
$$

Table 3 The parameters obtained from inverse analysis on 3FNL

\begin{tabular}{|c|c|c|c|c|c|c|}
\hline $\begin{array}{c}\text { Specimen } \\
\text { name }\end{array}$ & $\begin{array}{c}\sigma_{n, 1}^{c r} \\
{\left[\mathrm{~N} / \mathrm{mm}^{2}\right]}\end{array}$ & $\frac{\varepsilon_{n, 1}^{c r}}{\varepsilon_{n, u}^{c r}}$ & $\frac{\sigma_{n, 2}^{c r}}{\sigma_{n, 1}^{c r}}$ & $\frac{\varepsilon_{n, 2}^{c r}}{\varepsilon_{n, u}^{c r}}$ & $\frac{\sigma_{n, 3}^{c r}}{\sigma_{n, 1}^{c r}}$ & $\begin{array}{c}G_{f}^{I} \\
{[\mathrm{~N} / \mathrm{mm}]}\end{array}$ \\
\hline 3FNL & 3.00 & 0.05 & 1.24 & 0.80 & 0.40 & 7.95 \\
\hline
\end{tabular}

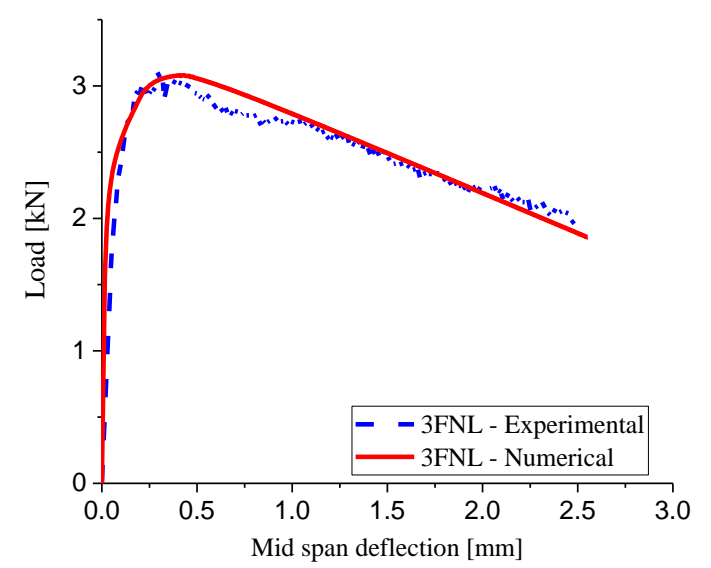

Fig. 6 Comparison between numerical and experimental flexural behavior of 3FNL

\subsection{Effectiveness assessment of RSFRM panels for the flexural strengthening of concrete beams}

FE analysis is first performed on a notched concrete beam with the dimensions recommended by RILEM TC 162-TDF [25] to obtain its behavior under three-point flexural loading. Subsequently, the strengthened concrete beam (Fig. 7) is analyzed to evaluate the effect of the strengthening panels on the flexural behavior of the beam. In Fig. 7, crack mouth opening displacement (CMOD) can be measured by using external LVDT located in the notched section of the beam.

Table 4 shows the model parameters adopted in the analysis of the concrete beam [26]. The panel is placed under the beam, and is not extended to the end supports due to the minor flexural stresses near the supports. Moreover, the thickness of the panel is obtained based on the true fiber distribution over the cross-sectional height of the specimens. Either a small thickness or a large thickness leads to a non-uniform distribution of fibers over the cross-sectional height of the specimens due to the SIFCON method which is assumed to produce the RSFRM panels. Therefore, an optimum thickness is required to produce a uniform specimen. Here, the assumed thickness is $2.3 \mathrm{~cm}$ which is obtained based on trial-and-error procedure. Also, a perfect bond is assumed between the strengthening panel and the beam. Figs. 8(a) and (b) indicate the meshes that are used for the FE analysis of the control beam and strengthened beam, respectively. The element size of the model decreases in the middle part to achieve a precise mesh independence analysis due to the crack propagation in this zone. 


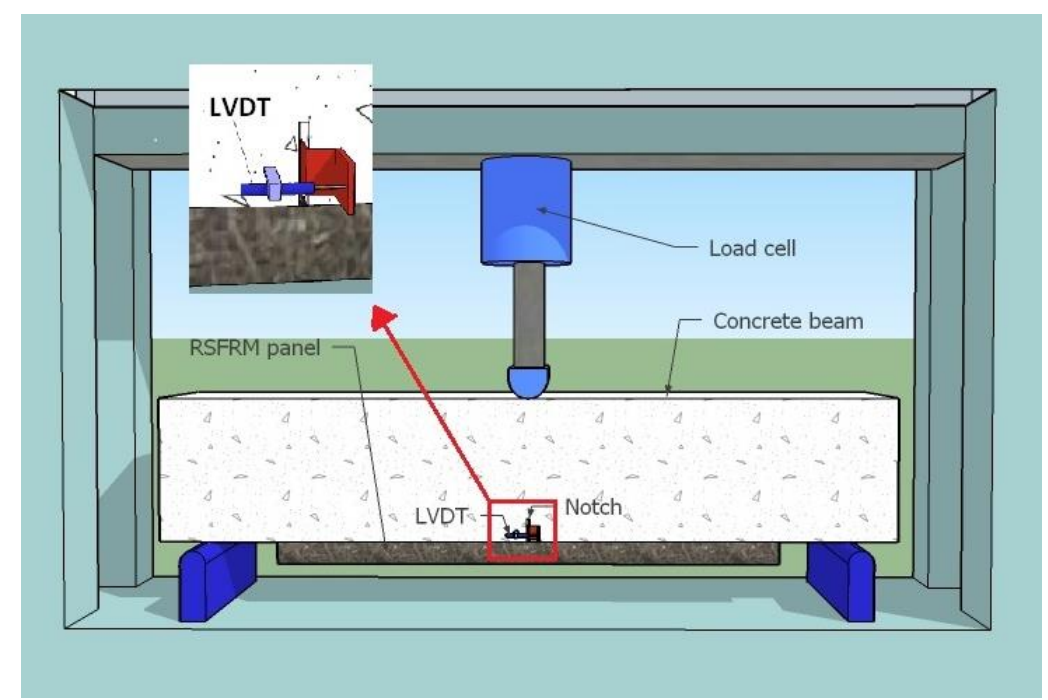

Fig. 7 Concrete beam strengthened with RSFRM panel

Table 4 The control concrete beam properties [26]

\begin{tabular}{|c|c|c|c|c|c|c|c|}
\hline $\begin{array}{c}\text { Specimen } \\
\text { name }\end{array}$ & $\begin{array}{c}f_{c}^{\prime} \\
{\left[\mathrm{N} / \mathrm{mm}^{2}\right]}\end{array}$ & $\begin{array}{c}f_{c t} \\
{\left[\mathrm{~N} / \mathrm{mm}^{2}\right]}\end{array}$ & $\frac{\varepsilon_{n, 1}^{c r}}{\varepsilon_{n, u}^{c r}}$ & $\frac{\sigma_{n, 2}^{c r}}{\sigma_{n, 1}^{c r}}$ & $\frac{\varepsilon_{n, 2}^{c r}}{\varepsilon_{n, u}^{c r}}$ & $\frac{\sigma_{n, 3}^{c r}}{\sigma_{n, 1}^{c r}}$ & $\begin{array}{c}G_{f}^{I} \\
{[\mathrm{~N} / \mathrm{mm}]}\end{array}$ \\
\hline Concrete & 39.7 & 2.2 & 0.005 & 0.3 & 0.1 & 0.3 & 0.086 \\
\hline
\end{tabular}

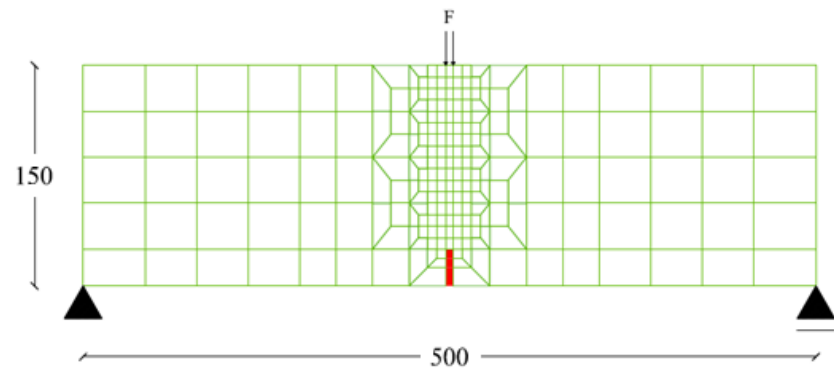

(a) FE mesh of the control beam

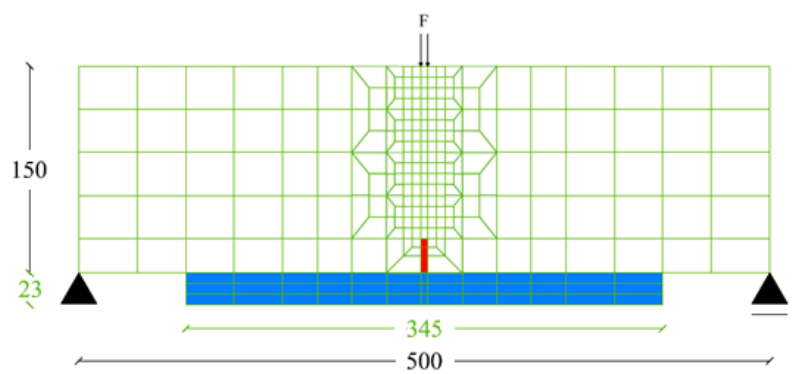

(b) FE mesh of the strengthened beam

Fig. 8 FE model of the control and strengthened beam

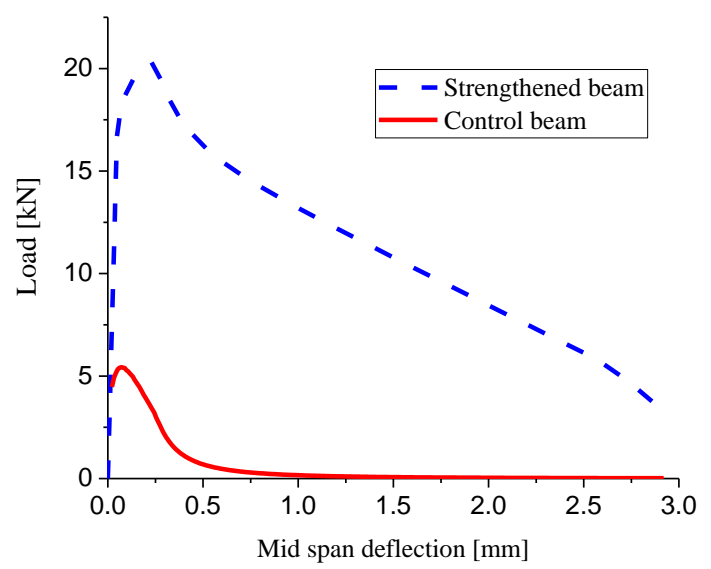

Fig. 9 Comparison between flexural behavior of control concrete beam and strengthened beam

Furthermore, a parametric study is performed to study the advantage of using the RSFRM panel instead of a panel made by plain cementitious material (PCM). Apart from the material properties of the PCM panel, the remaining simulation conditions including geometry, FE mesh, loading, and supports are the same in both analyses.

Fig. 9 illustrates the numerical three-point bending results of the control beam and strengthened beam. Four response stages are observed in Fig. 9. The first stage corresponds to the linear behavior of the uncracked specimen. In the second stage, the hardening zone starts at the deflection of $0.06 \mathrm{~mm}$ up to the peak load $(0.23 \mathrm{~mm})$. The first softening zone is observed after 
peak load as the third stage up to the deflection of $0.38 \mathrm{~mm}$. In the fourth region, a lower softening slope (second softening zone) of the curve is observed. Also, a comparison is made between the area under the load-deflection curves of the strengthened and control beam. The area under the load-deflection curve of the strengthened beam is 19.2 times larger than that of the control beam, which shows that the behavior of the beam changes significantly from a brittle to ductile post-cracking behavior.

Table 5 shows the results of the numerically modeled beams in terms of design parameters including the equivalent flexural tensile strength parameters $f_{e q, 2}$ and $f_{e q, 3}$, the maximum flexural tensile stress capacity $f_{\max }$, and the stress at the limit of proportionality $f_{c t, L}$. The limit of proportionality is the highest value of the load recorded up to a deflection of $0.05 \mathrm{~mm}$. The equivalent flexural tensile strength can be determined by Eqs. (7) and (8) [27].

$$
\begin{aligned}
& f_{e q, 2}=\frac{3}{2}\left(\frac{D_{B Z, 2, I}^{f}}{0.65}+\frac{D_{B Z, 2, I I}^{f}}{0.5}\right) \frac{L}{b h_{s p}^{2}} \\
& f_{e q, 3}=\frac{3}{2}\left(\frac{D_{B Z, 3, I}^{f}}{2.65}+\frac{D_{B Z, 3, I I}^{f}}{2.5}\right) \frac{L}{b h_{s p}^{2}}
\end{aligned}
$$

where $D_{B Z, 2, I}^{f}, D_{B Z, 2, I I}^{f}, D_{B Z, 3, I}^{f}$, and $D_{B Z, 3, I I}^{f}$ are the contribution of steel fibres to the energy absorption capacity (Fig. 10).

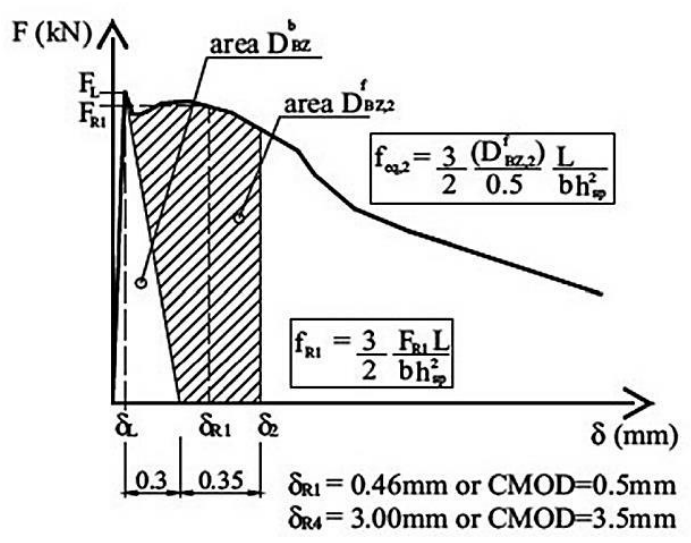

(a) Area under $F-\delta$ curve dedicated to the $f_{\text {eq, }}$

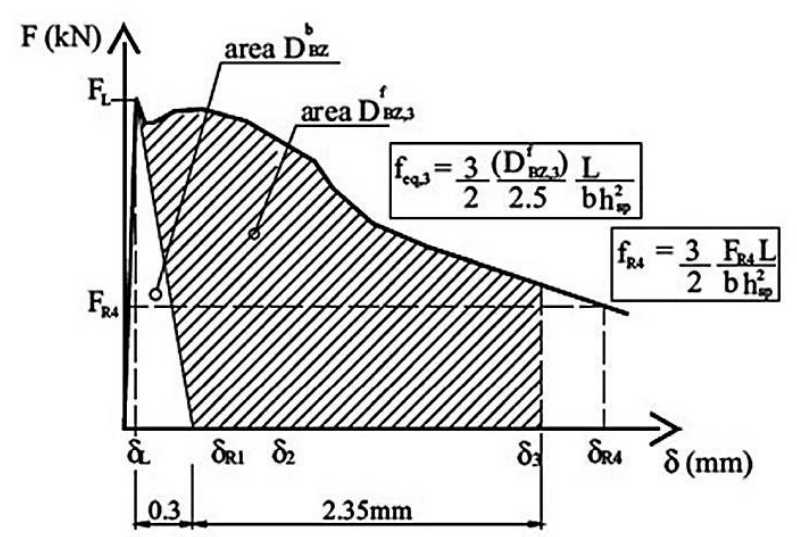

(b) Area under $F-\delta$ curve dedicated to the $f_{e q, 3}$

Fig. 10 Description of equivalent flexural tensile strength parameters [27]

The stress at the limit of proportionality and the maximum flexural tensile stress for the concrete beam strengthened by RSFRM panel are 3.20 and 3.76 times respectively higher than the corresponding stresses registered for the control beam.

Table 5 The stress at the limit of proportionality, the equivalent flexural tensile strength parameters, and the maximum flexural tensile stress capacity $[\mathrm{MPa}]$

\begin{tabular}{|c|c|c|c|c|}
\hline Specimens & $f_{c t, L}$ & $f_{\text {eq, }, 2}$ & $f_{\text {eq,3 }}$ & $f_{\max }$ \\
\hline Strengthened beam & 5.42 & 5.68 & 3.66 & 6.5 \\
\hline Control beam & 1.69 & 0.37 & 0.10 & 1.73 \\
\hline
\end{tabular}

According to the Whitney rectangular stress distribution [28], the nominal moment of the cross section $M_{n}$, is obtained from Eq. (9), where $f_{c}^{\prime}$ is the compressive strength of concrete, $f_{y}$ is the yield stress of rebars, $b$ is the width, and $d$ is the effective depth of the beam. In this equation, the values of 0.68 and 0.4 are considered for $\alpha$ and $\beta$ respectively, and $\rho$ is reinforcement ratio from Eq. (10) where $A_{s t}$ is the cross-section area of the steel reinforcement. Moreover, the load corresponding to the nominal moment is obtained from Eq. (11). Based on the mentioned equations and properties of the beam and longitudinal steel enforcement (ordinary steel bars), the flexural capacity of the beam provided by strengthening panels is equal to $77 \mathrm{~mm}^{2}$ cross section of longitudinal steel reinforcement with $f_{y}=300 \mathrm{Mpa}$. 


$$
\begin{aligned}
& M_{n}=\rho f_{y} b d^{2}\left(1-\frac{\beta f_{y} \rho}{\alpha f_{c}^{\prime}}\right) \\
& \rho=\frac{A_{s t}}{b d} \\
& P=\frac{4 M_{n}}{L}
\end{aligned}
$$

Fig. 11 compares the load-deflection relationship obtained when the beam is strengthened by the PCM and the RSFRM panel. The beam strengthened by the RSFRM panel provides 3.19 times higher flexural strength than the beam strengthened by the PCM panel. The RSFRM strengthening panel provides with an obvious nonlinear stage up to the peak load, followed by a relatively smooth softening response in the fourth stage with high ductility behavior. However, the beam strengthened by the PCM panel presents a brittle behavior with a very slight increase in the peak load. The comparison shows that RSF plays the most important role in improving the load carrying capacity and ductility of the strengthened beams.

The proposed method is also compared to two of the existing externally strengthening methods found in literature, i.e., fiber-reinforced self-consolidating concrete jackets containing glass fiber reinforced polymer (GFRP) bars [29] and precast textile RC panel [30]. The load carrying capacity increased by $250 \%$ and $46 \%$ in fiber-reinforced self-consolidating concrete jackets containing GFRP and precast textile RC panel, respectively. Compared to the existing methods, the $219 \%$ increase in flexural capacity achieved by the proposed method is effective.

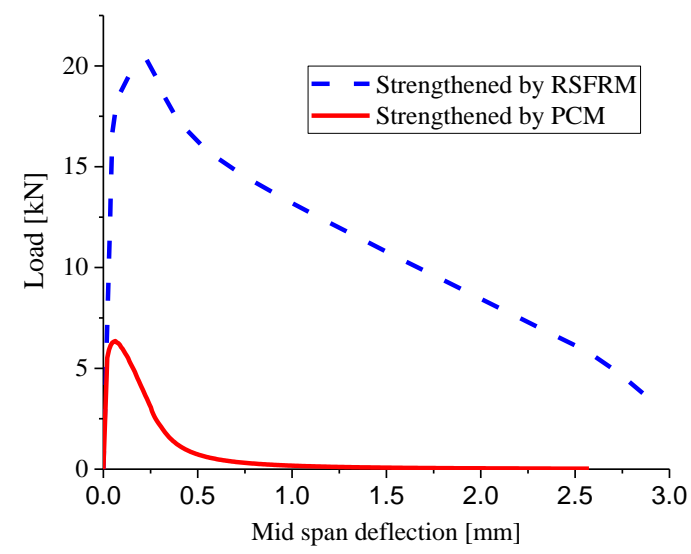

Fig. 11 Comparison between RSFRM and PCM panels' flexural strengthening capacity

\section{Conclusions}

This study presents an experimental and numerical investigation on the flexural strengthening of concrete beams using cement-based mortar panels reinforced with a relatively high content of RSFs. In the first part of this work, different mix designs were produced and tested to obtain the proper proportions in terms of compression and flexure. The second part of the paper was dedicated to the assessment of the potentiality of the panels produced with the selected mix design (3FNL) for the flexural strengthening of RC beams. An inverse analysis was performed on the results of the three-point bending test obtained for the specimen produced by the selected mix design to determine the required model parameters for FE analysis. Finally, FE analyses were performed on strengthened and non-strengthened concrete beams. The results determined from this study are as follows:

(1) Based on the results of the experimental program for developing a proper mix composition, a significant negative influence of introducing lime powder into the fiber-reinforced mortar specimens on the maximum flexural capacity of the RSFRM was verified. The comparisons showed that the most important role in the flexural strengthening is played by the RSFs. Therefore, a uniform mixture of fibers, as well as their quality, should be checked before construction. 
(2) RSFRM panels improved the maximum flexural load carrying capacity and ductility of the concrete beams by 3.19 and 19.2 times, respectively. Compared with the existing strengthening methods, the increase in flexural capacity and ductility achieved by the proposed eco-friendly and cost-effective strengthening method is effective, and it can be used as a reliable option for the flexural strengthening, especially when a medium strength is required.

(3) By applying the analytical formulations recommended by design codes, it was verified that the RSFRM panel can be also used as a partial replacement for longitudinal steel bars in RC beams. Thus, this method can be a valuable strengthening approach when the strengthening of an existing RC beam is required due to the inadequate longitudinal steel reinforcement. Also, these panels can be added in combination with the main reinforcement of the beams in cases where rebar density is a problem for providing the adequate spacing between the rebars.

\section{Acknowledgments}

The authors gratefully acknowledge the support and assistance provided by Civil Engineering Laboratory of Islamic Azad University (Bostanabad branch, Iran) and Khazar University (Baku, Azerbaijan) in manufacturing the specimens and carrying out the tests.

\section{Conflicts of Interest}

The authors declare no conflict of interest.

\section{References}

[1] M. Deng, M. Zhang, F. Ma, F. Li, and H. Sun, "Flexural Strengthening of Over-Reinforced Concrete Beams with Highly Ductile Fiber-Reinforced Concrete Layer," Engineering Structures, vol. 231, 111725, March 2021.

[2] T. C. Triantafillou, "Shear Strengthening of Reinforced Concrete Beams Using Epoxy-Bonded FRP Composites," ACI Structural Journal, vol. 95, no. 2, pp. 107-115, 1998.

[3] S. Aykac, I. Kalkan, B. Aykac, S. Karahan, and S. Kayar, "Strengthening and Repair of Reinforced Concrete Beams Using External Steel Plates,” Journal of Structural Engineering, vol. 139, no. 6, pp. 929-939, June 2013.

[4] H. T. Choi, J. S. West, and K. A. Soudki, “Analysis of the Flexural Behavior of Partially Bonded FRP Strengthened Concrete Beams," Journal of Composites for Construction, vol. 12, no. 4, pp. 375-386, August 2008.

[5] T. S. Lok and J. R. Xiao, "Flexural Strength Assessment of Steel Fiber Reinforced Concrete," Journal of Materials in Civil Engineering, vol. 11, no. 3, pp. 188-196, August 1999.

[6] A. K. H. Kwan and S. H. Chu, "Direct Tension Behaviour of Steel Fibre Reinforced Concrete Measured by a New Test Method,” Engineering Structures, vol. 176, pp. 324-336, December 2018.

[7] S. H. Chu and A. K. H. Kwan, "A New Bond Model for Reinforcing Bars in Steel Fibre Reinforced Concrete," Cement and Concrete Composites, vol. 104, 103405, November 2019.

[8] D. Burchart-Korol, "Life Cycle Assessment of Steel Production in Poland: A Case Study," Journal of Cleaner Production, vol. 54, pp. 235-243, September 2013.

[9] M. Mastali, A. Dalvand, A. R. Sattarifard, and M. Illikainen, "Development of Eco-Efficient and Cost-Effective Reinforced Self-Consolidation Concretes with Hybrid Industrial/Recycled Steel Fibers," Construction and Building Materials, vol. 166, pp. 214-226, March 2018.

[10] K. M. Liew and A. Akbar, "The Recent Progress of Recycled Steel Fiber Reinforced Concrete," Construction and Building Materials, vol. 232, 117232, January 2020.

[11] M. Leone, G. Centonze, D. Colonna, F. Micelli, and M. A. Aiello, "Fiber-Reinforced Concrete with Low Content of Recycled Steel Fiber: Shear Behaviour," Construction and Building Materials, vol. 161, pp. 141-155, February 2018.

[12] A. Simalti and A. P. Singh, "Comparative Study on Performance of Manufactured Steel Fiber and Shredded Tire Recycled Steel Fiber Reinforced Self-Consolidating Concrete,” Construction and Building Materials, vol. 266, 121102, January 2021.

[13] H. M. Elsanadedy, T. H. Almusallam, S. H. Alsayed, and Y. A. Al-Salloum, "Flexural Strengthening of RC Beams Using Textile Reinforced Mortar-Experimental and Numerical Study,” Composite Structures, vol. 97, pp. 40-55, March 2013. 
[14] Z. C. Tetta, L. N. Koutas, and D. A. Bournas, “Textile-Reinforced Mortar (TRM) Versus Fiber-Reinforced Polymers (FRP) in Shear Strengthening of Concrete Beams," Composites Part B: Engineering, vol. 77, pp. 338-348, August 2015.

[15] M. Herbrand, V. Adam, M. Classen, D. Kueres, and J. Hegger, "Strengthening of Existing Bridge Structures for Shear and Bending with Carbon Textile-Reinforced Mortar," Materials, vol. 10, no. 9, 1099, September 2017.

[16] Y. X. Du, X. Shao, S. H. Chu, F. Zhou, and R. K. L. Su, "Strengthening of Preloaded RC Beams Using Prestressed Carbon Textile Reinforced Mortar Plates," Structures, vol. 30, pp. 735-744, April 2021.

[17] N. Simoncello, P. Zampieri, J. Gonzalez-Libreros, and C. Pellegrino, "Experimental Behaviour of Damaged Masonry Arches Strengthened with Steel Fiber Reinforced Mortar (SFRM),” Composites Part B: Engineering, vol. 177, 107386, November 2019.

[18] L. Carabba, M. Santandrea, C. Carloni, S. Manzi, and M. C. Bignozzi, "Steel Fiber Reinforced Geopolymer Matrix (S-FRGM) Composites Applied to Reinforced Concrete Structures for Strengthening Applications: A Preliminary Study," Composites Part B: Engineering, vol. 128, pp. 83-90, November 2017.

[19] L. Lourenço, Z. Zamanzadeh, J. A. Barros, and M. Rezazadeh, "Shear Strengthening of RC Beams with Thin Panels of Mortar Reinforced with Recycled Steel Fibres,” Journal of Cleaner Production, vol. 194, pp. 112-126, September 2018.

[20] P. Balaguru and J. Kendzulak, "Mechanical Properties of Slurry Infiltrated Fiber Concrete (SIFCON)," Special Publication, vol. 105, pp. 247-268, 1987.

[21] A. F. M. Azevedo, J. A. O. Barros, J. M. Sena-Cruz, and A. Ventura-Gouveia, "Software no Ensino e no Projecto de Estruturas," III Congresso Luso-Moçambicano de Engenharia, Agosto 2003, pp. 81-92.

[22] E. N. Pereira, J. A. Barros, and A. Camões, "Steel Fiber-Reinforced Self-Compacting Concrete: Experimental Research and Numerical Simulation,” Journal of Structural Engineering, vol. 134, no. 8, pp. 1310-1321, August 2008.

[23] J. Sena-Cruz, J. A. Barros, A. Fernandes, Á. F. Azevedo, and A. Camões, "Stress-Crack Opening Relationship of Enhanced Performance Concrete," 9th Portuguese Conference on Fracture, February 2004, pp. 1-9.

[24] J. A. Barros, R. Gettu, and B. Barragán, "Material Nonlinear Analysis of Steel Fibre Reinforced Concrete Beams Failing in Shear," 6th International RILEM Symposium on Fibre Reinforced Concrete, September 2004, pp. 711-720.

[25] L. Vandewalle, D. Nemegeer, L. Balazs, B. Barr, J. Barros, P. Bartos, et al., " $\sigma-\varepsilon$-Design Method," Materials and Structures, vol. 36, no. 8, pp. 560-567, October 2003.

[26] J. A. Barros, H. Baghi, S. J. Dias, and A. Ventura-Gouveia, “A FEM-Based Model to Predict the Behaviour of RC Beams Shear Strengthened According to the NSM Technique,” Engineering Structures, vol. 56, pp. 1192-1206, November 2013.

[27] L. Vandewalle, "Bending Test," Materials and Structures, vol. 33, no. 1, pp. 3-5, January 2000.

[28] C. S. Whitney, "Design of Reinforced Concrete Members Under Flexure or Combined Flexure and Direct Compression," Concrete International: Design and Construction, vol. 26, no. 5, pp. 21-36, 2004.

[29] H. S. Attar, M. R. Esfahani, and A. Ramezani, "Experimental Investigation of Flexural and Shear Strengthening of RC Beams Using Fiber-Reinforced Self-Consolidating Concrete Jackets,” Structures, vol. 27, pp. 46-53, October 2020.

[30] Y. J. You, H. Y. Kim, G. S. Ryu, K. T. Koh, G. H. Ahn, and S. H. Kang, "Strengthening of Concrete Element with Precast Textile Reinforced Concrete Panel and Grouting Material,” Materials, vol. 13, no. 17, 3856, September 2020.

Copyright $\odot$ by the authors. Licensee TAETI, Taiwan. This article is an open access article distributed under the terms and conditions of the Creative Commons Attribution (CC BY-NC) license (https://creativecommons.org/licenses/by-nc/4.0/). 